\title{
童电

\section{ANÁLISE DOS PARÂMETROS PARA GERAÇÃO DE ENERGIA SOLAR FOTOVOLTAICA NO ACRE, BRASIL}

\section{ANALYSIS OF PARAMETERS FOR PHOTOVOLTAIC SOLAR ENERGY GENERATION IN ACRE, BRAZIL}

\section{ANÁLISIS DE PARÁMETROS PARA LA GENERACIÓN DE ENERGÍA SOLAR FOTOVOLTAICA EN ACRE, BRASIL}

Vivyane Alencar Marques Araújo do Nascimento

Mestranda pelo Programa de Pós-Graduação em Ciência, Inovação e Tecnologia para Amazônia da

Universidade Federal do Acre - UFAC.

vivyane.marques.mv@gmail.com / http://orcid.org/0000-0003-2187-2863

\section{Taynara Bastos Trindade}

Mestranda pelo Programa de Pós-Graduação em Ciência, Inovação e Tecnologia para Amazônia da

Universidade Federal do Acre - UFAC.

taynarabastos.eng@gmail.com / http://orcid.org/0000-0003-2791-0023

\section{Clarice Maia Carvalho}

Doutora em Biotecnologia pela Universidade Federal do Amazonas - UFAM. Professora do Programa de Pós-Graduação em Ciência, Inovação e Tecnologia para Amazônia da Universidade

Federal do Acre - UFAC.

claricemaiacarvalho@gmail.com / http://orcid.org/0000-0003-1092-738X

Recebido: 03/03/2021; Aceito: 13/08/2021; Publicado: 12/10/2021.

\section{RESUMO}

Energia solar é obtida através de placas solares fotovoltaicas com a função de captar a energia do sol e transformar em energia elétrica, aumentando a geração de energia solar nas regiões com maior captação de energia luminosa. Assim, neste artigo analisou-se os parâmetros para geração de energia solar fotovoltaica no Acre, Brasil. Coletou-se dados referentes a insolação, temperaturas máximas e mínimas, precipitação e umidade relativa no Instituto Nacional de Meteorologia, irradiação solar, no Centro de Referências para Energias Solar e Eólica Sérgio de S. Brito, regionais do Vale do Juruá e Vale do Acre, no período de 2015-2020. As análises foram quantitativas, utilizando o cálculo da média e cálculo do plano inclinado. Na comparação das regionais, o Vale do Acre apresentou melhores resultados para geração de energia solar e com um ângulo com a maior média diária anual de irradiação solar, considerando-se projetar-se células fotovoltaicas na regional. $O$ trabalho apresenta que o Acre possui bastante insolação e irradiação solar, indicando alto potencial de geração de energia solar para as regionais do estado.

Palavras-chave: Eficiência Fotovoltaica; Radiação Solar; Temperatura da Célula Fotovoltaica; Irradiação.

\section{ABSTRACT}

Solar energy is obtained through photovoltaic solar panels with the function of capturing the sun's energy and transforming it into electrical energy, increasing the generation of solar energy in regions with greater capture of light energy. Thus, the parameters for the generation of photovoltaic solar energy in Acre, Brazil were analyzed. Data on insolation, maximum and minimum temperatures, 
|Análise dos parâmetros para geração de energia solar fotovoltaica no Acre, Brasil |

| Vivyane Alencar Marques Araújo do Nascimento | Taynara Bastos Trindade |

| Clarice Maia Carvalho|

precipitation and relative humidity were collected at the National Institute of Meteorology, solar irradiation, at the Reference Center for Solar and Wind Energy Sérgio de S. Brito, regions of Vale do Juruá and Vale do Acre, in the period 2015-2020. Analyzes were quantitative, using mean calculation and inclined plane calculation. When comparing the regions, Vale do Acre presented better results for solar energy generation and with an angle with the highest annual daily average of solar irradiation, considering the project of photovoltaic cells in the region. The work shows that Acre has a lot of insolation and solar irradiation, indicating a high potential for generating solar energy for the regional regions of the state.

Keywords: Photovoltaic Efficiency; Solar Radiation; Photovoltaic Cell Temperature; Irradiation.

\section{RESUMEN}

La energía solar se obtiene a través de paneles solares fotovoltaicos con la función de captar la energía del sol y transformarla en energía eléctrica, aumentando la generación de energía solar en las regiones con mayor captación de energía luminosa. Así, se analizaron los parámetros para la generación de energía solar fotovoltaica en Acre, Brasil. Los datos sobre insolación, temperaturas máximas y mínimas, precipitación y humedad relativa fueron recolectados en el Instituto Nacional de Meteorología, irradiación solar, en el Centro de Referencia de Energía Solar y Eólica Sérgio de S. Brito, regiones de Vale do Juruá y Vale do Acre, en el período 2015-2020. Los análisis fueron cuantitativos, utilizando cálculo de medias y cálculo de plano inclinado. Al comparar las regiones, Vale do Acre presentó mejores resultados para la generación de energía solar y con un ángulo con el promedio diario anual más alto de irradiación solar, considerando el diseño de células fotovoltaicas en la región. El trabajo muestra que Acre tiene mucha insolación e irradiación solar, lo que indica un alto potencial de generación de energía solar para las regiones regionales del estado.

Palabras clave: Eficiencia Fotovoltaica; Radiación Solar; Temperatura de la Celda Fotovoltaica; Irradiación.

\section{INTRODUÇÃO}

Um dos principais recursos necessários para o homem é a energia, devendo ser consideradas novas formas de gerar energia com as condições geográficas brasileiras, sendo o uso da energia fotovoltaica uma opção excelente. Hoje, aproximadamente $2 \%$ da energia total brasileira vêm da energia fotovoltaica (FRANCISCO et al., 2019).

A fonte de energia responsável e necessária ao desenvolvimento de todos os ciclos da natureza é a radiação solar, todavia seu aproveitamento é limitado. A ideia do aproveitamento desse recurso surgiu com as teorias da termodinâmica, por meio do aquecimento de líquidos ou gases e, seguidamente, com os estudos sobre o efeito fotoelétrico (SOUZA; ARISTONE, 2016).

Há diversos desafios para que a fonte de energia renovável conhecida como energia solar fotovoltaica seja implantada com menores obstáculos, o que é importante fazer um panorama desta modalidade de geração no país para suprir esses desafios (ROSA; GASPARIN, 2016).

Em projetos de sistemas fotovoltaicos existem variedades de ferramentas computacionais para auxílio. Certas associam a seleção de banco de dados climatológicos, 
|Análise dos parâmetros para geração de energia solar fotovoltaica no Acre, Brasil |

| Vivyane Alencar Marques Araújo do Nascimento | Taynara Bastos Trindade| | Clarice Maia Carvalho|

formas básicas de modelagem tridimensional, escolha da tecnologia de diferentes fabricantes e simulação solar, que possibilita o avanço no dimensionamento do projeto, análise dos efeitos do sombreamento e a estimativa de geração de energia de sistemas fotovoltaicos (HERRERO et al., 2017).

Entender os valores de irradiação solar em superfície é importante para o desenvolvimento de projetos em energia solar, sendo alcançados através de radiômetros instalados em determinados locais ou publicações como em atlas de energia solar (SOUZA et al., 2018).

Por causa do alto investimento e necessidade de manutenção e operação constantes em estações solarimétricas ou meteorológicas, elas não dispõem de sensores para medição da irradiação difusa, dificultando assim a coleta de irradiação solar (SOUZA et al., 2018).

Um fator a se considerar na geração de energia solar é a irradiação solar captada de forma inclinada. Para todas as capitais brasileiras a irradiação solar apresenta valores que variam entre $4,9 \mathrm{kWh} / \mathrm{m}^{2}$ por dia e $6 \mathrm{kWh} / \mathrm{m}^{2}$ por dia, retratando uma alta uniformidade de irradiação solar no território nacional (MOREIRA JUNIOR; SOUZA, 2020).

O sistema fotovoltaico é formado por três módulos fotovoltaicos de $100 \mathrm{Wp}$ conectados em paralelo, instalados com suas faces voltadas para o norte geográfico e com um ângulo de inclinação de $33^{\circ}$, que é o valor da latitude local $+10^{\circ}$. Esses dados são fornecidos pelo fabricante para a condição padrão de operação, sendo eles radiação solar de $1000 \mathrm{~W} / \mathrm{m}^{2}$ e temperatura de $25^{\circ} \mathrm{C}$, sujeitas a variações de $10 \%$ e uma insolação média diária de 4,5 horas de pico (SOUZA; ARISTONE, 2018).

Frente a falta de informação sobre a geração de energia solar no Acre, o presente trabalho tem por objetivo analisar os parâmetros para geração de energia solar fotovoltaica no estado do Acre, Brasil.

\section{MATERIAL E MÉTODOS}

\section{Coleta de dados}

Os dados foram coletados no Instituto Nacional de Meteorologia (INMET) através do site < $\underline{\text { https://portal.inmet.gov.br/> }}$, para condições climáticas para análise do potencial de instalação de projetos de produção de energia solar. Já para irradiação solar, os dados foram coletados no Centro de Referências para Energias Solar e Eólica Sérgio de S. Brito

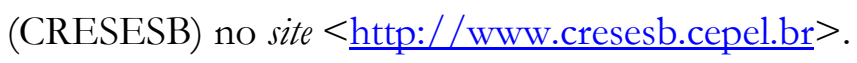


|Análise dos parâmetros para geração de energia solar fotovoltaica no Acre, Brasil|

| Vivyane Alencar Marques Araújo do Nascimento | Taynara Bastos Trindade | | Clarice Maia Carvalho|

A área escolhida para base de dados foi o estado do Acre, localizado na Região Norte do Brasil, para a geração de energia solar fotovoltaica, servindo como comparação as regionais do Vale do Juruá e Vale do Acre, no período de 2015 a 2020.

Para as coletas, foram selecionadas as cidades de Tarauacá, pertencente ao Vale do Juruá (regional do Tarauacá/Envira) e Rio Branco, pertencente ao Vale do Acre (regional do Baixo Acre), que possuíam estações meteorológicas operantes com dados completos no período selecionado para estudo.

A Figura 1 apresenta as regionais selecionadas para extração dos dados do INMET. Observa-se o mapa do Brasil em A, e o mapa do Acre em B, destacando o Vale do Juruá e Vale do Acre e as estações meteorológicas de onde foram extraídos os dados em Tarauacá e Rio Branco.

Figura 1 - A. Mapa do Brasil; B. Mapa do Acre, destacando o Vale do Juruá e Vale do Acre.

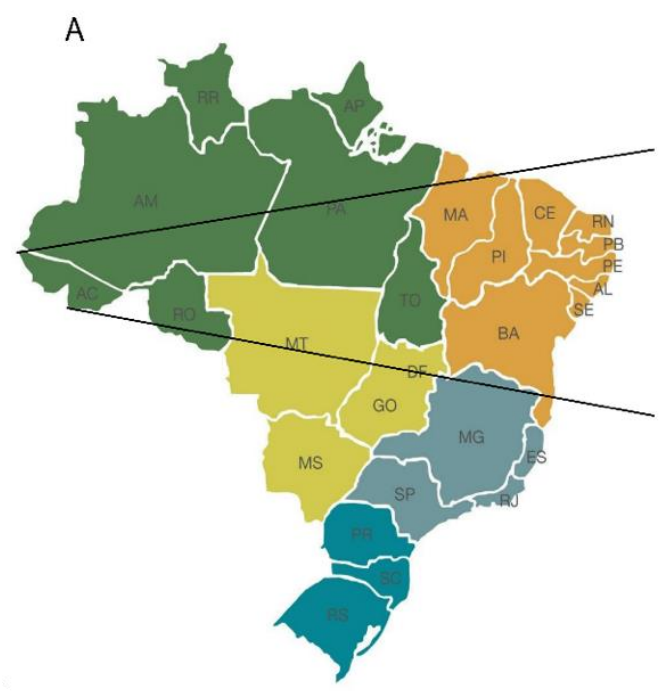

B

Fonte: GOOGLE MAPS - Base de dados. Elaboração própria.

Os parâmetros coletados do banco de dados do INMET foram: insolação, considerando a insolação dada em horas; precipitação em milímetros; nebulosidade em décimos; temperaturas máximas e mínimas em graus Celsius e umidade relativa em percentual (SILVA; SOUZA, 2016).

O INMET, conforme cada estação meteorológica da região, recolhe dados para as análises do tempo meteorológico, onde os instrumentos localizados nas estações são capazes de registrar a radiação solar entre outras variáveis. A Tabela 1 apresenta a descrição e coordenadas geográficas das estações de coleta dos dados do INMET. 
|Análise dos parâmetros para geração de energia solar fotovoltaica no Acre, Brasil|

| Vivyane Alencar Marques Araújo do Nascimento | Taynara Bastos Trindade |

| Clarice Maia Carvalho|

Tabela 1 - Descrição e coordenadas geográficas, latitude, longitude, altitude das estações localizadas na regional Tarauacá/Envira e Baixo Acre com a sua situação e periodicidade de precipitação.

\begin{tabular}{cccccccc}
\hline Regional & Local & $\begin{array}{c}\text { Código } \\
\text { estação }\end{array}$ & Latitude & Longitude & Altitude & Situação & $\begin{array}{c}\text { Periodicidade } \\
\text { de precipitação }\end{array}$ \\
\hline Tarauacá/Envira & Tarauacá & 82807 & -8.16027 & -70.76861 & 172.27 & Operante & Mensal \\
Baixo Acre & Rio Branco & 82915 & -9.95916 & -67.86888 & 160.71 & Operante & Mensal \\
\hline \multicolumn{7}{c}{ Fonte: INMET - Base }
\end{tabular}
Fonte: INMET - Base de dados. Elaboração própria.

O parâmetro extraído do CRESESB utiliza o programa SunData, versão 3.0, destinado ao potencial solar, calcula a irradiação solar diária média mensal no território nacional e possui como base de dados o Atlas Brasileiro de Energia Solar (2a edição), elaborado com climatologia e condições atmosféricas sazonais típicas observadas no Brasil (PEREIRA et al., 2017), atualizado em 2017, sendo o mais moderno ao se tratar de informações de irradiação solar no Brasil.

Para a extração na base de dados do CRESESB, utiliza-se as coordenadas geográficas de latitude e longitude que corresponde as diárias médias mensais de irradiação do ano de 2017. A Tabela 2 apresenta as coordenadas utilizadas na busca dos dados de irradiação solar nas localidades estudadas do Vale de Juruá e Vale do Acre, além das distâncias do ponto de referência das estações para as inclinações do plano horizontal, ângulo, média anual e mínimo mensal, considerando as inclinações para orientação das placas solares para o Norte $(\mathrm{N})$.

Tabela 2 - Coordenadas geográficas, latitude, longitude, distância do ponto de referência das estações para as inclinações do plano horizontal, ângulo, média anual e mínimo mensal localizadas na regional

\begin{tabular}{|c|c|c|c|}
\hline Região & & Vale do Juruá & Vale do Acre \\
\hline \multirow{6}{*}{$\begin{array}{c}\text { Regional } \\
\text { Estação } \\
\text { Município } \\
\text { Latitude } \\
\text { Longitude } \\
\text { Distância do ponto de } \\
\text { referência } \\
\text { (Latitude; Longitude) }\end{array}$} & & Tarauacá/Envira & Baixo Acre \\
\hline & & Tarauacá & Rio Branco \\
\hline & & Tarauacá, Acre, Brasil & $\begin{array}{c}\text { Rio Branco, Acre, } \\
\text { Brasil }\end{array}$ \\
\hline & & $8,201^{\circ} \mathrm{S}$ & $10,001^{\circ} \mathrm{S}$ \\
\hline & & $70,749^{\circ} \mathrm{O}$ & $67,849^{\circ} \mathrm{O}$ \\
\hline & & $5,0 \mathrm{~km}$ & $5,1 \mathrm{~km}$ \\
\hline \multirow{4}{*}{ Inclinação } & Plano Horizontal & $0^{\circ} \mathrm{N}$ & $0^{\circ} \mathrm{N}$ \\
\hline & $\begin{array}{c}\text { Ângulo igual a } \\
\text { latitude }\end{array}$ & $8^{\circ} \mathrm{N}$ & $10^{\circ} \mathrm{N}$ \\
\hline & $\begin{array}{l}\text { Maior média } \\
\text { anual }\end{array}$ & $8^{\circ} \mathrm{N}$ & $10^{\circ} \mathrm{N}$ \\
\hline & $\begin{array}{l}\text { Maior mínimo } \\
\text { mensal }\end{array}$ & $6^{\circ} \mathrm{N}$ & $10^{\circ} \mathrm{N}$ \\
\hline
\end{tabular}

Fonte: CRESESB - Base de dados. Elaboração própria.

\section{Métodos}


|Análise dos parâmetros para geração de energia solar fotovoltaica no Acre, Brasil |

| Vivyane Alencar Marques Araújo do Nascimento | Taynara Bastos Trindade | | Clarice Maia Carvalho|

O teste estatístico foi realizado nos dados coletados pelo INMET e aplicado a média para apresentar os dados mensais em médias anuais no período de 2015-2020 nos parâmetros coletados de insolação, precipitação, nebulosidade, temperatura máxima e mínima e umidade relativa. Assim, pode-se expressar estatisticamente os dados distribuídos uniforme para cada situação analisada.

A fórmula utilizada na média foi:

$$
M_{e}=\frac{X_{1}+X_{2}+X_{n}+\cdots+X_{n}}{n}
$$

Onde:

$M_{e}:$ média;

$X_{1}+X_{2}+X_{3}+\cdots+X_{n}$ : valores dos dados mensais;

n: número de elementos do conjunto de dados mensais.

Os valores de irradiação solar coletados pelo CRESESB são convertidos do plano horizontal para o plano inclinado, sendo coletado o ângulo igual a latitude, o ângulo que fornece o maior valor médio diário anual e maior mínimo diário anual para auxiliar na análise de melhor plano para a geração de energia solar fotovoltaica da região escolhida.

O cálculo do plano inclinado para a irradiação levou-se em consideração as seguintes análises de busca no banco de dados do CRESESB, para as médias mensais de irradiação do ano de 2017:

- Coordenadas geográficas;

- Ângulos de inclinações são arredondadas para valores inteiros de graus, que se constituem numa melhor precisão para coleta de dados;

- Valor mínimo de inclinação é de $10^{\circ}$ conforme orientado pela CEPEL e utilizados na base de dados;

- Ângulo de inclinação B, pelos critérios de latitude, maior média e maior mínimo, calculado pelo seguinte intervalo:

$$
\text { Latitude }-20 \leq \mathrm{B} \leq \text { Latitude }+20 \text {, com passos de } 1^{\circ}
$$

\section{Análise de dados}

Foi analisado os dados através da planilha construída no Excel 2016, onde organizou-se os dados coletados do INMET, no período de 2015 a 2020, realizando uma análise inicial entre Vale do Juruá e o Vale do Acre, observando-se cada mês o nível de insolação, nebulosidade, precipitação, umidade e as temperaturas máximas e mínimas para uma comparação entre as regionais. 
|Análise dos parâmetros para geração de energia solar fotovoltaica no Acre, Brasil |

| Vivyane Alencar Marques Araújo do Nascimento | Taynara Bastos Trindade | | Clarice Maia Carvalho|

Para a análise de dados de irradiação solar pelo CRESESB, foi constituída uma planilha no Excel 2016, com os dados coletados de 2017 e organizados para uma análise do plano horizontal, ângulo igual a latitude, maior média anual e maior mínimo mensal para o estudo de maior geração anual de energia entre as regionais do estado.

Posteriormente, os dados foram organizados em tabelas, gráficos e figuras para apresentações dos resultados das análises realizadas nos dados coletados do INMET e CRESESB, e assim verificar os parâmetros para geração de energia solar fotovoltaica no Acre, Brasil.

\section{RESULTADOS E DISCUSSÃO}

Ao comparar as regiões do Vale do Juruá e o Vale do Acre, no período de 2015 a 2020, com as cidades Tarauacá e Rio Branco, contatou-se que houve diferenças nas variáveis de insolação, temperaturas máximas e mínimas, precipitação e umidade relativa. Apesar de estarem no mesmo estado, possuem um nível diferente para cada variável que contribui na geração de energia solar.

Em relação a irradiação solar, o ângulo com a maior média diária anual, analisando o período de janeiro a dezembro de 2017, foi o Vale do Acre, sendo considerada, assim, como a região com melhor capacidade de geração de energia solar fotovoltaica.

\section{Descrição e análise dos dados}

Os dados completos obtidos do INMET encontram-se na Tabela 3, onde foram coletados os dados das regionais Vale do Juruá e Vale do Acre. Assim, pode-se observar a média da insolação (h), precipitação $(\mathrm{mm})$, nebulosidade (décimos), temperaturas $\left({ }^{\circ} \mathrm{C}\right)$ máximas e mínimas e umidade relativa (\%). Com esses dados iniciais, é possível observar que o Vale do Acre possui maior capacidade para gerar energia solar fotovoltaica, por possuir maior insolação em relação ao Vale do Juruá, devido a região ter menor índice de precipitação e nebulosidade. 
|Análise dos parâmetros para geração de energia solar fotovoltaica no Acre, Brasil|

| Vivyane Alencar Marques Araújo do Nascimento | Taynara Bastos Trindade |

| Clarice Maia Carvalho|

Tabela 3 - Dados de insolação $(\mathrm{h})$, precipitação $(\mathrm{mm})$, nebulosidade (décimos) temperaturas máximas e mínimas $\left({ }^{\circ} \mathrm{C}\right)$ e umidade relativa (\%) coletados no INMET no período 2015-2020 e local do Vale do Juruá e Vale do Acre.

\begin{tabular}{|c|c|c|c|c|c|c|c|c|}
\hline \multirow[t]{2}{*}{ Dado } & \multirow[t]{2}{*}{ Regional } & \multicolumn{6}{|c|}{ Ano } & \multirow[b]{2}{*}{ Média } \\
\hline & & 2015 & 2016 & 2017 & 2018 & 2019 & 2020 & \\
\hline \multirow{2}{*}{$\begin{array}{c}\text { Insolação } \\
\text { (h) }\end{array}$} & VJ & 144,567 & null & null & null & null & null & 144,56 \\
\hline & VA & 170,48 & 171,24 & 164,65 & 160,70 & 170,29 & 161,63 & 166,63 \\
\hline \multirow{2}{*}{$\begin{array}{l}\text { Precipitação } \\
\text { (mm) }\end{array}$} & VJ & 247,75 & 183,05 & 205,48 & 190,23 & 220,04 & 239,92 & 211,53 \\
\hline & VA & 167,70 & 140,14 & 187,04 & 187,25 & 232,82 & 141,37 & 176,54 \\
\hline \multirow{2}{*}{$\begin{array}{l}\text { Nebulosidade } \\
\text { (décimos) }\end{array}$} & VJ & 6,73 & 6,27 & 6,75 & 6,95 & 7,23 & 6,77 & 6,78 \\
\hline & VA & 6,39 & 6,33 & 6,52 & 6,38 & 5,89 & 5,70 & 6,21 \\
\hline \multirow{2}{*}{$\begin{array}{l}\text { Temperatura } \\
\text { máxima }\left({ }^{\circ} \mathrm{C}\right)\end{array}$} & VJ & 32,16 & 32,47 & 32,18 & 31,71 & 32,06 & 32,33 & 32,14 \\
\hline & VA & 32,31 & 32,72 & 32,33 & 31,78 & 32,49 & 32,92 & 32,41 \\
\hline \multirow{2}{*}{$\begin{array}{l}\text { Temperatura } \\
\text { mínima }\left({ }^{\circ} \mathrm{C}\right)\end{array}$} & VJ & 22,77 & 22,47 & 22,24 & 22,08 & 22,50 & 22,44 & 22,41 \\
\hline & VA & 22,45 & 21,90 & 21,92 & 21,60 & 22,03 & 22,06 & 21,99 \\
\hline \multirow{2}{*}{$\begin{array}{c}\text { Umidade } \\
\text { relativa (\%) }\end{array}$} & VJ & 88,05 & 84,25 & 83,52 & 83,13 & 84,21 & 85,00 & 84,67 \\
\hline & VA & 84,77 & 83,12 & 85,78 & 85,84 & 85,80 & 82,47 & 84,693 \\
\hline
\end{tabular}

VJ = Vale do Juruá; VA = Vale do Acre; null = valor nulo. Fonte: INMET - Base de dados. Elaboração própria.

A coleta de dados obtida pelo CRESESB, no período de janeiro a dezembro de 2017, para a análise de irradiação solar nas regionais do Vale do Juruá e Vale do Acre, destaca-se que no plano horizontal, no ângulo igual a latitude, a maior média anual e o maior mínimo mensal, possuem uma diferença entre as variáveis das regionais. Assim, o Vale do Acre possui maior irradiação solar em relação ao Vale do Juruá com diferença de 1 (um) grau.

Tabela 4 - Irradiação solar diária média mensal $\left[\mathrm{kWh} / \mathrm{m}^{2}\right.$.dia $]$ nos ângulos do plano horizontal, ângulo igual a latitude, maior média anual e maior mínimo mensal coletados no CRESESB no período janeiro a dezembro de 2017 no local do Vale do Juruá e Vale do Acre.

\begin{tabular}{|c|c|c|c|c|c|c|c|c|}
\hline \multicolumn{9}{|c|}{ Irradiação solar diária média mensal $\left[\mathrm{kWh} / \mathrm{m}^{2}\right.$.dia $]$} \\
\hline \multirow{2}{*}{$\begin{array}{c}\text { Ângulo } \\
\text { Regional }\end{array}$} & \multicolumn{2}{|c|}{$\begin{array}{c}\text { Plano } \\
\text { Horizontal }\end{array}$} & \multicolumn{2}{|c|}{$\begin{array}{l}\text { Ângulo igual a } \\
\text { latitude }\end{array}$} & \multicolumn{2}{|c|}{$\begin{array}{c}\text { Maior média } \\
\text { anual }\end{array}$} & \multicolumn{2}{|c|}{$\begin{array}{c}\text { Maior mínimo } \\
\text { mensal }\end{array}$} \\
\hline & VJ & VA & VJ & VA & VJ & VA & VJ & VA \\
\hline Janeiro & 4,56 & 4,47 & 4,37 & 4,26 & 4,37 & 4,26 & 4,42 & 4,26 \\
\hline Fevereiro & 4,8 & 4,61 & 4,69 & 4,48 & 4,69 & 4,48 & 4,72 & 4,48 \\
\hline Março & 4,24 & 4,22 & 4,23 & 4,22 & 4,23 & 4,22 & 4,24 & 4,22 \\
\hline Abril & 4,4 & 4,41 & 4,52 & 4,57 & 4,52 & 4,57 & 4,49 & 4,57 \\
\hline Maio & 4,09 & 3,95 & 4,3 & 4,21 & 4,3 & 4,21 & 4,25 & 4,21 \\
\hline Junho & 4,12 & 4,09 & 4,4 & 4,46 & 4,4 & 4,46 & 4,33 & 4,46 \\
\hline Julho & 4,34 & 4,26 & 4,62 & 4,62 & 4,62 & 4,62 & 4,55 & 4,62 \\
\hline Agosto & 5,01 & 4,87 & 5,22 & 5,13 & 5,22 & 5,13 & 5,17 & 5,13 \\
\hline Setembro & 5,19 & 5,1 & 5,25 & 5,18 & 5,25 & 5,18 & 5,24 & 5,18 \\
\hline Outubro & 5,12 & 5,11 & 5,03 & 5 & 5,03 & 5 & 5,06 & 5 \\
\hline Novembro & 4,84 & 5,04 & 4,66 & 4,8 & 4,66 & 4,8 & 4,71 & 4,8 \\
\hline Dezembro & 4,53 & 4,61 & 4,33 & 4,36 & 4,33 & 4,36 & 4,39 & 4,36 \\
\hline Média & 4,6 & 4,56 & 4,64 & 4,61 & 4,64 & 4,61 & 4,63 & 4,61 \\
\hline
\end{tabular}


|Análise dos parâmetros para geração de energia solar fotovoltaica no Acre, Brasil |

| Vivyane Alencar Marques Araújo do Nascimento | Taynara Bastos Trindade | | Clarice Maia Carvalho|

Para Silva et al. (2018), a irradiação, irradiância, temperatura do ar, umidade relativa do ar, precipitação pluviométrica e velocidade do vento modificam-se e para melhorar o desempenho do sistema de geração solar, poderiam estar sob condições de maior irradiância solar, menor precipitação pluviométrica, menor temperatura, maior velocidade do vento e menor umidade relativa do ar (SILVA et al., 2018).

\section{Nebulosidade}

Ao analisar a nebulosidade entre o Vale do Juruá e Vale do Acre, conclui-se que, para ambas as regiões no intervalo de tempo analisado, tem-se uma tendência de maior nebulosidade do Vale do Juruá em todos os anos, pois a região possui uma faixa de nebulosidade conhecida como a Zona de Convergência do Atlântico Sul, uma característica da climatologia da América do Sul.

Ainda assim, a regional que possui menos nebulosidade é a do Vale do Acre, possibilitando ter aumento maior de radiação e pouca interferência da zona de Convergência do Atlântico Sul, onde terá uma melhor performance na geração de energia solar. A Figura 2 apresenta a média de nebulosidade no período de 2015-2020 em décimos, com dados extraídos do INMET para o do Vale do Juruá e Vale do Acre.

Figura 2 - Média da nebulosidade do Vale do Juruá e Vale do Acre no período 2015-2020.

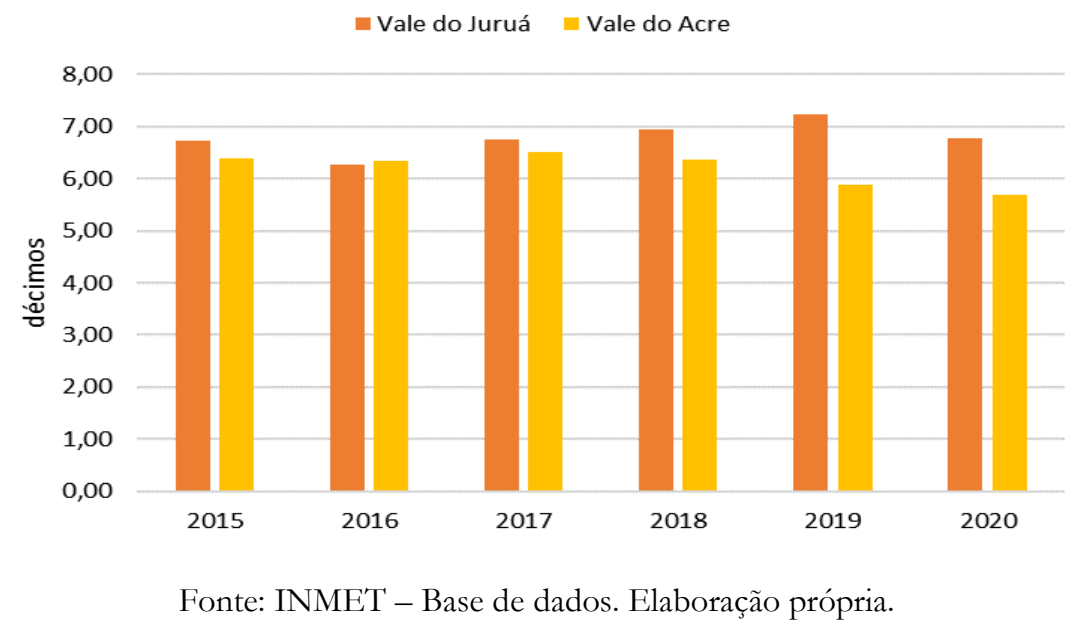

Chaves e Sobrinho (2019) afirmam que a Zona de Convergência do Atlântico Sul constitui um dos principais fenômenos meteorológicos de escala sinótica em atuação na América do Sul. 
|Análise dos parâmetros para geração de energia solar fotovoltaica no Acre, Brasil |

| Vivyane Alencar Marques Araújo do Nascimento | Taynara Bastos Trindade | | Clarice Maia Carvalho|

Em relação à capacidade de transformação de energia solar em energia elétrica ser afetada em dias com bastante nebulosidade, Silva e Souza (2016) discutem que, a essa transformação de energia solar em energia elétrica afetada pela nebulosidade não irá vir a ser extinta devido ao fato que a radiação solar difusa é capaz de chegar às placas solares fotovoltaicas, assim em meses nebulosos ainda se pode aproveitar um pouco da radiação solar para outros fins.

\section{Precipitação}

$\mathrm{Na}$ região Norte ocorre maior precipitação em relação às outras regiões do país. Ao analisar o Vale do Juruá e Vale do Acre, observa-se na Figura 3 a média de precipitação no período de 2015-2020 nas regionais do Acre. Assim, pode-se observar que no Vale do Juruá ocorre maior precipitação ao longo dos anos analisados, fazendo com que essa região, por ser mais chuvosa, tenha menor geração de energia através das placas solares por haver redução da reflexão da luz do sol em períodos chuvosos. O Vale do Acre obteve alta precipitação no ano de 2019, e em 2016 e 2020 um baixo nível. O Vale do Juruá obteve elevadas precipitações nos anos de 2015 e 2020.

Figura 3 - Média de precipitação do Vale do Juruá e Vale do Acre no período 2015-2020.

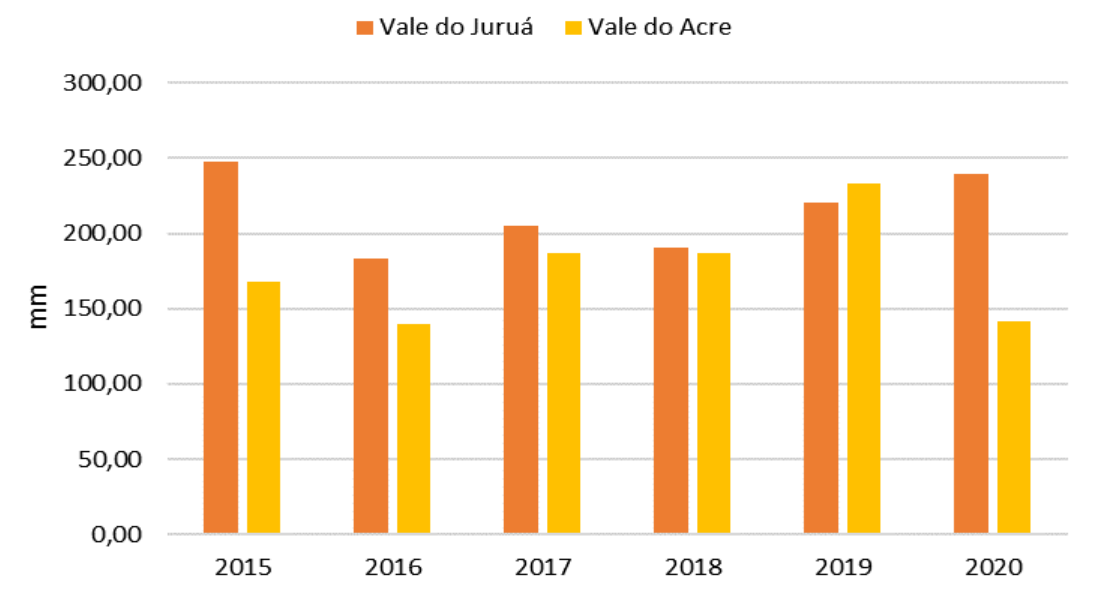

Fonte: INMET - Base de dados. Elaboração própria.

A Zona de Convergência do Atlântico Sul é responsável pela ocorrência de precipitações volumosas, principalmente na primavera e verão, em que a sua intensidade e manutenção é determinante para formação de instabilidades e precipitações intensas (CHAVES; SOBRINHO, 2019). 
|Análise dos parâmetros para geração de energia solar fotovoltaica no Acre, Brasil |

| Vivyane Alencar Marques Araújo do Nascimento | Taynara Bastos Trindade | | Clarice Maia Carvalho|

Pereira et al. (2017), através do Atlas Brasileiro de Energia Solar, afirmam que a região com maior precipitação média alta é a Amazônia, que influencia a região Norte do Brasil a possuir bastante umidade, possuindo muita atividade convectiva ao longo do ano, principalmente, entre os meses de novembro a março.

Outra influência da alta umidade na região Norte é a vinda da Amazônia junto com a Alta da Bolívia (PEREIRA et al., 2017). E o aumento da umidade do ar produz maior precipitação pluviométrica e reduz a irradiância direta, fazendo-se assim com que a geração de energia solar seja menor quando a precipitação é elevada (SILVA et al., 2018).

\section{Umidade e Temperaturas}

Para a geração de energia solar através de placas solares, requer-se também uma análise da umidade relativa e temperaturas, embora essa tecnologia possua um bom desempenho nesses parâmetros. Sobre a umidade relativa média no período de 2015-2020 para as duas regionais, pôde-se observar que as regionais do Vale do Juruá e Vale do Acre são regiões que se caracterizam por elevada umidade por conta de suas baixas latitudes, fazendo com que o Vale do Acre, por ter menos altitude, apresentasse elevada umidade nos anos de 2017, 2018 e 2019, variando entre 85\% e 86\%, e no Vale do Juruá em 2015 houve um pico de umidade com 88,05\%, enquanto que em 2020 a baixa umidade esteve predominante no Vale do Acre, com 82,47\% (Figura 4 A).

A Figura 4 B apresenta as temperaturas máximas e mínimas do Vale do Juruá e Vale do Acre no período de 2015-2020. Observou-se que tanto na temperatura máxima quanto na mínima seguem-se de forma igual, pois se trata do mesmo estado. No Vale do Juruá com temperatura média máxima de $32,14^{\circ} \mathrm{C}$ e no Vale do Acre média máxima de $32,43^{\circ} \mathrm{C}$ para todos os anos, proporcionando uma melhor radiação nas temperaturas máximas que é observada no Vale do Acre nos anos de 2016, 2019 e 2020, variando entre $32^{\circ} \mathrm{C}$ e $33^{\circ} \mathrm{C}$. 
|Análise dos parâmetros para geração de energia solar fotovoltaica no Acre, Brasil|

| Vivyane Alencar Marques Araújo do Nascimento | Taynara Bastos Trindade | | Clarice Maia Carvalho|

Figura 4 - A. Umidade relativa média do Vale do Juruá e Vale do Acre no período 2015-2020; B. Médias das temperaturas máximas e mínimas do Vale do Juruá e Vale do Acre no período 2015-2020.

A

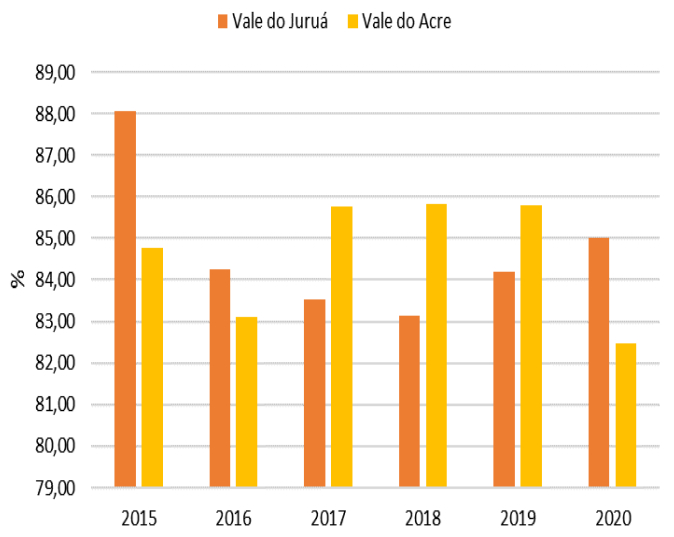

$\mathrm{B}$

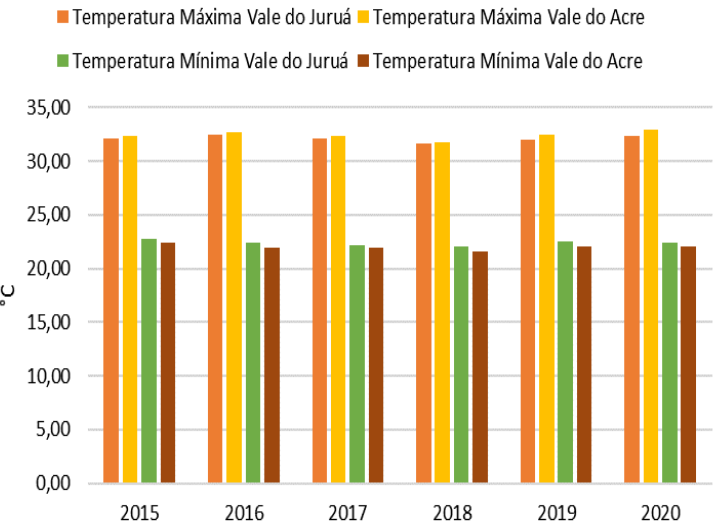

Fonte: INMET - Base de dados. Elaboração própria.

As relações da umidade relativa do ar com a quantidade de água dispersa como suspensão na atmosfera estão relacionadas, onde, a radiação solar atinge uma gota de água no ar que sofre reflexão, refração e difração, fazendo com que a quantidade de radiação direta que atinge uma superfície seja menor no período seco, assim, com períodos de baixa umidade relativa do ar (CANTOR, 2017; SILVA et al., 2018).

Em relação à umidade, Silva et al. (2018) observaram que, quanto maior for a umidade relativa do ar, menor é o índice de claridade, fazendo com que a irradiância direta sobre a superfície de captação acarrete redução da produtividade do sistema fotovoltaico. E quanto às temperaturas, os autores afirmam ainda que o vento interfere no desempenho do sistema fotovoltaico, atuando no processo de troca de calor pelo ambiente, reduzindo a temperatura das células fotovoltaicas, ou seja, com velocidade do vento sendo maior, a troca de calor na superfície de uma célula solar torna-se maior.

\section{Insolação}

A estação meteorológica da região do Vale do Juruá, conforme dados do INMET, não coletou dados de insolação no período de 2016 a 2020, mas somente no ano de 2015, conforme observa-se na Figura 5 A. Para o ano de 2015, a insolação média, que representa o número de horas que a localidade recebe de radiação solar, foi de 144,567 h.

$\mathrm{Na}$ Figura 5 B estão apresentadas a média de horas de insolação do Vale do Acre no período de 2015-2020, para todos os anos a insolação média varia entre 161,63 h a 170,48 h, mostrando que a região, por estar próxima à linha do Equador, os índices de insolação são maiores, possuindo, assim, uma alta capacidade de geração de energia solar. 
|Análise dos parâmetros para geração de energia solar fotovoltaica no Acre, Brasil|

| Vivyane Alencar Marques Araújo do Nascimento | Taynara Bastos Trindade | | Clarice Maia Carvalho|

Apesar de o Vale do Juruá estar também próximo à linha do Equador e possuir os mesmos parâmetros de insolação na região, ele é afetado pela sua latitude um pouco acima que o Vale do Acre, fazendo com que sua insolação seja um pouco abaixo. Como observado no ano de 2015 (Figura 5 A), o Vale do Juruá apresentou uma média de insolação de 144,567 h e o Vale do Acre com uma média de insolação de 170,48 h (Figura $5 \mathrm{~B})$.

Figura 5 - A. Média de horas de insolação do Vale do Juruá no período 2015-2020. B. Média de horas de insolação do Vale do Acre no período 2015-2020.

A

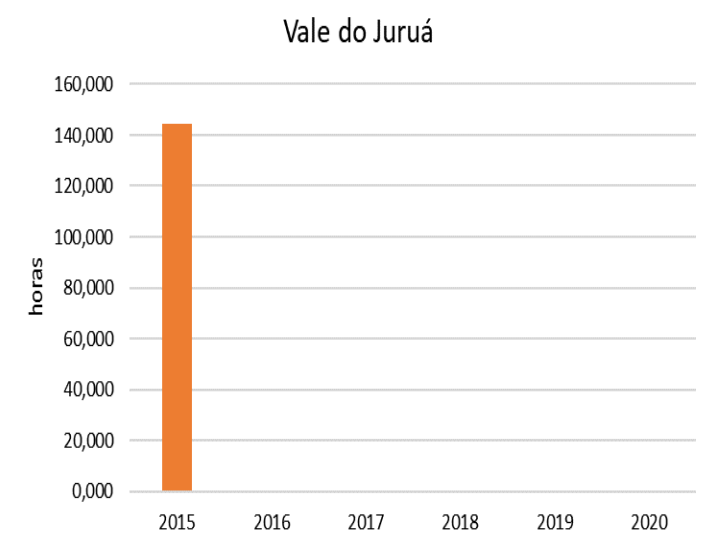

B

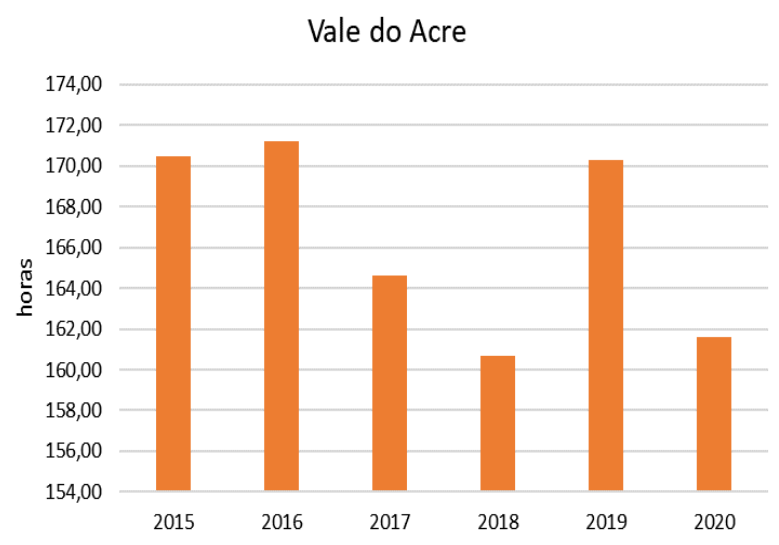

Fonte: INMET - Base de dados. Elaboração própria.

O Atlas Brasileiro de Energia Solar declara que a distribuição da irradiação solar no Brasil é elevada, contudo ainda é abaixo do necessário para a produção de calor em relação às altas temperaturas durante todo o ano. Assim, é necessário ter altas horas de insolação direta (PEREIRA et al., 2017). Pereira et al. (2017) afirmam ainda que todas as regiões brasileiras, exceto o semiárido nordestino, apresentam períodos com alta nebulosidade e chuvas, prejudicando as horas de insolação.

\section{Irradiação Solar}

Coletados os dados do CRESESB, que utiliza o programa SunData versão 3.0 e calcula a irradiação solar diária média mensal no território nacional, ao coletar e analisar os dados, foi possível obter a irradiação solar diária $\mathrm{em} \mathrm{kWh} / \mathrm{m}^{2}$ do Vale do Juruá e do Vale do Acre no período de janeiro a dezembro do ano de 2017 (Figura 6). Pôde-se observar que, para aproveitar o potencial de energia, a incidência de irradiação está disponível por metros quadrados nas duas regiões, sendo analisada pela maior média anual. Assim, o Vale do Acre possui a maior média anual de irradiação solar em relação ao Vale do Juruá. 
|Análise dos parâmetros para geração de energia solar fotovoltaica no Acre, Brasil |

| Vivyane Alencar Marques Araújo do Nascimento | Taynara Bastos Trindade | | Clarice Maia Carvalho|

Pôde-se observar ainda que o plano horizontal permite verificar o melhor lugar para serem instaladas placas solares, e o Vale do Acre possui elevado plano horizontal por conta da irradiação local da região estar superior em relação ao Vale do Juruá (Figura 6). Entre agosto e outubro obteve-se o ângulo igual a latitude nas duas regiões. Esse ângulo influencia no plano inclinado e ajuda a identificar os meses de maior irradiação solar na região.

Figura 6 - Irradiação solar diária entre o Vale do Juruá e o Vale do Acre no período de janeiro a dezembro de 2017.

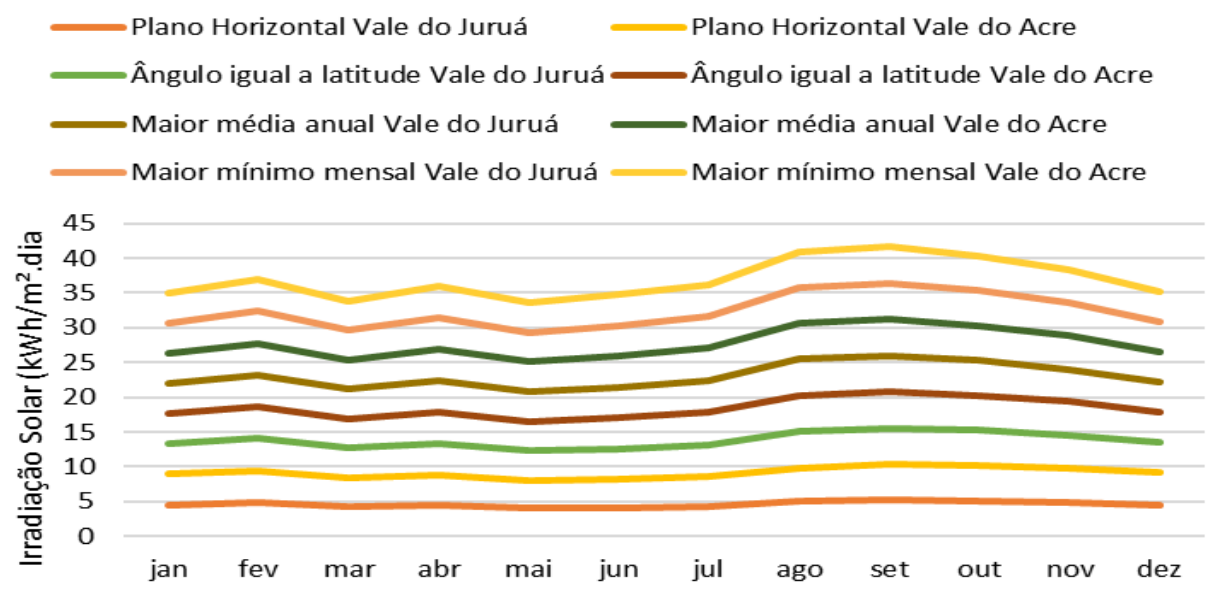

Fonte: CRESESB - Base de dados. Elaboração própria.

A geração de energia solar implica em estudar a melhor irradiação solar para um melhor dimensionamento das placas solares fotovoltaicas. Portanto, a irradiação diária constitui um dos melhores parâmetros a serem analisados, pois as placas trabalham na conversão em unidades kWh, que incidem na área das placas (SILVA; SOUZA, 2016).

Em relação a outros países, o Brasil tem potencial de energia solar muito grande e, de acordo com as estações do ano de cada região, a radiação solar no Brasil vem sendo de 1500 a $2300 \mathrm{kWh} / \mathrm{m}^{2}$ por ano. Em contrapartida, na Alemanha é 900 a $1250 \mathrm{kWh} / \mathrm{m}^{2}$ ao ano. O Brasil apresenta essa característica de maior radiação pelo fato de sua extensa localização entre os trópicos de Câncer e Capricórnio, possibilitando a recepção de altas taxas de radiação, praticamente chegando a ser perpendicular, assim, aumentando o potencial de energia fotovoltaica nas regiões do país (FRANCISCO et al., 2019).

\section{CONCLUSÃO}

O estado do Acre apresenta grande potencial de geração de energia solar fotovoltaica através do seu sistema de células solares. Ao comparar as regiões do Vale do 
|Análise dos parâmetros para geração de energia solar fotovoltaica no Acre, Brasil|

| Vivyane Alencar Marques Araújo do Nascimento | Taynara Bastos Trindade | | Clarice Maia Carvalho|

Juruá e o Vale do Acre, no período de 2015 a 2020, foram constatadas diferenças nas variáveis de insolação, temperaturas máximas e mínimas, precipitação e umidade relativa.

O Vale do Juruá possui tendência de maior nebulosidade, ocorre maior precipitação e temperatura aceitável. Assim, a região caracteriza-se por elevada umidade por conta de sua baixa latitude que influencia para que sua insolação seja mais abaixo que a do Vale do Acre. A irradiação solar possui um ângulo com a maior média diária anual no Vale do Acre, colocando, assim, como a região com maior potencial de geração de energia solar fotovoltaica.

O estado do Acre possui bastante insolação e eleva o potencial de geração de energia solar para as regiões do Vale do Juruá e Vale do Acre.

\section{REFERÊNCIAS}

CANTOR, G. A. R. Influência dos fatores climáticos no desempenho de módulos fotovoltaicos em regiões de Clima Tropical. 2017. Dissertação (Mestrado em Energias Renováveis) - Universidade Federal da Paraíba, João Pessoa, 2017.

CHAVES, S. V. V.; SOBRINHO, W. F. R. C. A contribuição da Zona de Convergência do Atlântico Sul nas precipitações no mês de dezembro de 2018 e seus impactos sobre a cidade de Teresina-PI. SIMPÓSIO BRASILEIRO DE GEOGRAFIA FÍSICA APLICADA, 18., 2019, Fortaleza. Anais... Fortaleza: UFC, 2019.

FRANCISCO, A. C. C. [et al.]. Influência de parâmetros meteorológicos na geração de energia em painéis fotovoltaicos: um caso de estudo do Smart Campus Facens, SP, Brasil. Urbe. Revista Brasileira de Gestão Urbana, v. 11, n. 1, p. 1-15, e20190027, 2019.

HERRERO, R.; SIMPlíCIO, R. S.; MOURA, C. B.; ZUFFO, M. K. Método de localização de módulos FV utilizando estimativa da irradiação incidente e aproximação pela qualidade elétrica do módulo. Revista Brasileira de Energia Solar, v. 8, n. 1, p. 1-9, 2017.

MOREIRA-JUNIOR, O.; SOUZA, C. C. Aproveitamento fotovoltaico, análise comparativa entre Brasil e Alemanha. Interações (Campo Grande), v. 21, n. 2, p. 379-387, 2020.

PERREIRA, E. B. [et al.]. Atlas Brasileiro de Energia Solar. 2. ed. São José dos Campos: INPE, 2017.

ROSA, A. R. O.; GASPARIN, F. P. Panorama da energia solar fotovoltaica no Brasil. Revista Brasileira de Energia Solar, v. 7, n. 2, p. 140-147, 2016.

SILVA, G. D. P.; SOUZA, M. J. R. Análise de variáveis de projetos de sistema solar fotovoltaico utilizando o modelo SAM: uma comparação entre Belém, Fortaleza e Brasília. Revista Brasileira de Energias Renováveis, v. 5, n. 2, p. 297-312, 2016.

SILVA, J. A. A. [et al.]. Tratamento e análise de dados solarimétricos da estação meteorológica da EMC/UFG. CONGRESSO BRASILEIRO DE ENERGIA SOLAR, 8., 
| Vivyane Alencar Marques Araújo do Nascimento | Taynara Bastos Trindade| | Clarice Maia Carvalho|

2018, Gramado. Anais eletrônicos... Gramado-RS: ABNS/UFRGS, 2018. Disponível em:

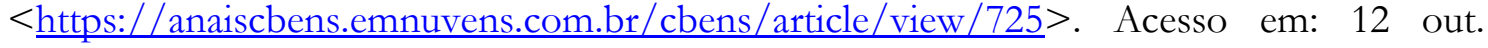
2021.

SOUZA, A.; ARISTONE, F. Estudo da eficiência energética de células fotovoltaicas em função da radiação solar no centro-oeste brasileiro. InterEspaço: Revista de Geografia e Interdisciplinaridade, v. 2 , n. 7, p. 115-128, set./dez. 2016. Disponível em: < http://dx.doi.org/10.18764/2446-6549.v2n7p115-128>. Acesso em: 12 out. 2021.

SOUZA, A.; ARISTONE, F. Um estudo da temperatura e da irradiação solar em células fotovoltaicas. Tecno-Lógica, v. 22, n. 2, p. 194-200, 2018. Disponível em:

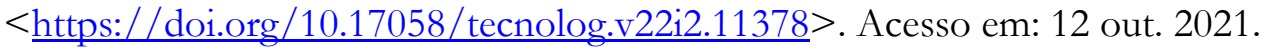

SOUZA, M. B.; TONOLO, E. A.; YANG, R. L.; TIEPOLO, G. M.; URBANETZ JUNIOR, J. Determinação difusa a partir da irradiação global horizontal - estudo para a cidade de Curitiba. Smart Energy, v. 1, n. 1, p. 1-6, 2018.

\section{Como citar:}

\section{ABNT}

NASCimentO, V. A. M. A.; TRINDADE, T. B.; CARVALHO, C. M. Análise dos parâmetros para geração de energia solar fotovoltaica no Acre, Brasil. InterEspaço: Revista de Geografia e Interdisciplinaridade, v. 7, e202129, 2021. Disponível em: <http://dx.doi.org/10.18764/2446-6549.e202129>. Acesso em: 12 out. 2021.

\section{APA}

Nascimento, V. A. M. A., Trindade, T. B., \& Carvalho, C. M. Análise dos parâmetros para geração de energia solar fotovoltaica no Acre, Brasil. InterEspaço: Revista de Geografia e Interdisciplinaridade, v. 7, e202129. Recuperado em 12 outubro, 2021, de http://dx.doi.org/10.18764/2446-6549.e202129

\section{@creative}

This is an open access article under the CC BY Creative Commons 4.0 license.

Copyright (C) 2021, Universidade Federal do Maranhão.

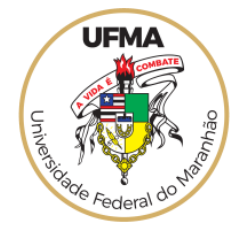

